\title{
EFFICACY OF THREE DENTURE BRUSHES ON BIOFILM REMOVAL FROM COMPLETE DENTURES
}

\author{
Roseana Aparecida Gomes FERNANDES ${ }^{1}$, Cláudia Helena LOVATO - SILVA², \\ Helena de Freitas Oliveira PARANHOS ${ }^{3}$, Izabel Yoko ITO ${ }^{4}$
}

\author{
1- DDS, MSc, PhD, Graduate Student, Department of Dental Materials and Prosthodontics, School of Dentistry of Ribeirão Preto, University \\ of São Paulo, Ribeirão Preto, SP, Brazil. \\ 2- DDS, MSc, PhD, Assistant Professor, Department of Dental Materials and Prosthodontics, School of Dentistry of Ribeirão Preto, University \\ of São Paulo, Ribeirão Preto, SP, Brazil. \\ 3- DDS, MSc, PhD, Associate Professor, Department of Dental Materials and Prosthodontics, School of Dentistry of Ribeirão Preto, University \\ of São Paulo, Ribeirão Preto, SP, Brazil. \\ 4- DDS, MSc, PhD, Full Professor, Department of Clinical Analysis, Toxicology and Bromatology, School of Pharmaceutical Sciences of \\ Ribeirão Preto, University of São Paulo, Ribeirão Preto, SP, Brazil.
}

Corresponding address: Roseana Aparecida Gomes Fernandes - Rua Juruá, 123 - Vila Virgínia, Cep.: 14030-410 - Ribeirão Preto, São Paulo, Brasil - e-mail: roseana.fernandes@ig.com.br - phone: 5516 - 36378180 - fax: 5516 - 36024780

Received: March 22, 2006 - Modification: May 17, 2006 - Accepted: June 30, 2006

\begin{abstract}
T

he aim of this study was to compare the efficacy of three denture brushes (Bitufo-B; Medic Denture-MD; Colgate-C) on biofilm removal from upper and lower dentures using a specific dentifrice (Corega Brite). The correlation between biofilm levels on the internal and external surfaces of the upper and lower dentures was also evaluated. A microbiological assay was performed to assess the growth of colony-formed units (cfu) of Candida yeasts on denture surface. Thirty-three patients were enrolled in a 10-week trial divided in two stages: 1 (control) - three daily water rinses within 1 week; 2 - three daily brushings within 3 weeks per tested brush. Internal (tissue) and external (right buccal flange) surfaces of the complete dentures were disclosed (neutral red 1\%) and photographed. Total denture areas and disclosed biofilm areas were measured using Image Tool 3.00 software for biofilm quantification. Dentures were boxed with \#7 wax and culture medium (CHROMagar ${ }^{\mathrm{TM}}$ Candida) was poured to reproduce the internal surface. Statistical analysis by Friedman's test showed significant difference $(p<0.01)$ between control and brushing stages. No difference was found among the brushes with respect to their efficacy on biofilm removal $(\mathrm{p}>0.01)$. Analysis by the Correlation test showed higher $\mathrm{r}$ values $(\mathrm{B}=0.78 ; \mathrm{MD}=0.8341, \mathrm{C}=0.7362)$ for the lower dentures comparing the surfaces (internal and external) and higher $r$ values $(B=0.7861, M D=0.7955, C=0.8298)$ for the external surface comparing the dentures (upper and lower). The results of the microbiological showed no significant difference $(\mathrm{p}>0.01$ ) between the brushes with respect to the frequency of the species of yeasts (chi-square test). In conclusion, all denture brushes evaluated in this study were effective in the removal of biofilm. There was better correlation of biofilm levels between the surfaces for the lower dentures, and between the dentures for the external surface. There was no significant difference among the brushes regarding the frequency of yeasts.
\end{abstract}

Uniterms: Complete denture; Biofilm; Hygiene; Brushes.

\section{INTRODUCTION}

The literature has shown the correlation between poor hygiene and lesions in the oral mucosa of complete dentures wearers, mainly chronic atrophic candidiasis. Furthermore, the colonization of the internal surface of dentures can act as reservoir for dissemination of infections, such as gastrointestinal and pleuropulmonary infections ${ }^{9}$. Recent studies have also suggested that biofilm accumulation is an important etiologic factor for caries and periodontal disease in teeth that are retainers of overdentures or are adjacent to prosthetic devices. The defective cleansing of complete dentures has also been a reason of concern ${ }^{6}$. Ideally, denture care products should be easy of handling, effective for removal of inorganic/organic deposits and stains, bactericidal and fungicidal, non-toxic to the patient, nondeleterious to the denture materials and inexpensive. Given that brushing is the most common cleansing method for complete dentures, the use of specific brushes and dentifrices is of paramount importance for good outcomes ${ }^{3,6}$.

In most clinical experiments, the levels of biofilm are evaluated on the internal surface of upper complete dentures ${ }^{10}$. In some studies, other surfaces are also

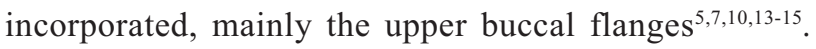


Reports on the assessment of both dentures (upper and lower), however, are not common ${ }^{10}$. Despite the advances in the development of hygiene products, specific products for complete dentures are still needed, as well as studies addressing the effectiveness of such products, aiming at the selection of adequate methods and materials for complete denture cleansing. The purpose of this study was to evaluate the effectiveness of three denture brushes on removal of biofilm from the external and internal surfaces of upper and lower complete dentures. The number of colony-forming units (cfu) of Candida yeasts on denture surfaces was also assessed microbiologically.

\section{MATERIALAND METHODS}

Thirty-three denture wearers ( 9 male and 17 female, aged 36 to 80 years) were enrolled in a 10 -week trial period using a brushing method with three specific denture brushes (Bitufo; Bitufo, Itupeva, São Paulo, Brazil; Medic Denture; Condor SA, São Bento do Sul, SC, Brazil; Colgate; ColgatePalmolive, São Bernardo do Campo, SP, Brazil - Figure 1) and a specific dentifrice (Corega; Brite Stafford-Miller Indústria Ltda, Rio de Janeiro, RJ, Brazil). The trial was divided in two stages: 1 (control) - three daily water rinses within 1 week; 2- three daily brushings within 3 weeks, for each denture brush.

Every week, the internal (tissue) and external (right buccal flange) surfaces of upper and lower dentures were disclosed with an aqueous solution of $1 \%$ neutral red. The dentures were positioned on a clamp (Universal Adriática S/A, São Paulo, SP, Brazil - intermediate shank at $0^{\circ}$ ), the camera was

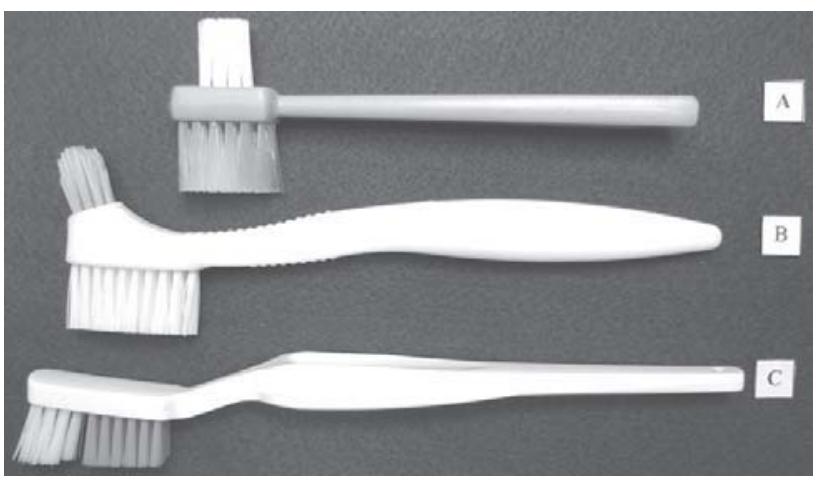

FIGURE 1- Denture brushes: A- Bitufo; B - Medic Denture C - Colgate fixed on a stand (CS-4 Copy Stand Testrite, Newark, NJ, USA) and the denture surfaces were photographed (digital camera, Coolpix, Nikon, Melville, NY, USA) at $90^{\circ}$ with standardized film-object distance and exposure time. Thereafter, the disclosed biofilm was removed with a specific denture brush (Jonhson \& Jonhson, São Paulo, SP, Brazil Paranhos et. al. ${ }^{10}$ ) and liquid soap (JOB - Chemistry Cleaning Products Ltda, Ribeirão Preto, SP, Brazil) and returned to the patients.

The photographs were transferred to a computer and entered in Adobe Photoshop 5.5 software (Adobe Systems Inc., San Jose, CA, USA). The total denture area and the area of disclosed biofilm were measured using Image Tool software (Windows, version 3.0, UTHSC, San Antonio, TX, USA). The percentages of biofilm-covered areas were calculated as the ratio between disclosed areas and denture total surface areas multiplied by 100 .

Nine patients were submitted to microbiological assay to assess the contamination by yeasts after biofilm disclosure $^{12}$. Dentures were boxed using a \#7 wax strip, which was positioned by contouring all denture periphery on its external side and CHROMagar ${ }^{\mathrm{TM}}$ Candida was poured to reproduce the internal surface. After incubation, the number of colony-forming units (cfu) was counted and the species of yeasts were identified under microscopy using a color code for each species.

Data were analyzed statistically by Friedman' test, Correlation test and chi-square test at 5\% significance level.

\section{RESULTS}

Table 1 shows the biofilm percent means obtained for the upper and lower dentures while Table 2 shows the results of Friedman' test applied to the data on Table 1. There were statistically significant differences $(\mathrm{p}<0.01)$ between the control and the brushing stages. Friedman's test was also applied to calculate the biofilm means for each denture brush. No statistically significant difference $(\mathrm{p}<0.01)$ was found between the brushes regarding biofilm removal.

Table 3 shows the results of the Correlation test applied to verify the existence of correlation between dentures (upper and lower) and surfaces (internal and external) the) and the biofilm levels. Table 4 shows the frequency of all species of yeasts for each denture brush; no significant difference was found by chi-square test $(p>0.01)$.

TABLE 1- Biofilm percent means from internal and external surfaces of upper and lower dentures

Denture

\begin{tabular}{lcccccc} 
& \multicolumn{2}{c}{ Internal } & & \multicolumn{2}{c}{ External } \\
& Bitufo & Medic Denture & Colgate & Bitufo & Medic Denture & Colgate \\
\hline Upper & 13,30 & 12.09 & 12.42 & 12.81 & 13.22 & 13.41 \\
Lower & 19.13 & 18.49 & 18.61 & 11.53 & 10.49 & 10.47 \\
\hline
\end{tabular}




\section{DISCUSSION}

Poor denture hygiene is often associated with lack of orientation, characteristics of the prosthesis, reduction of patient's manual dexterity and lack of specific cleansing products on the market. Denture cleansing products are not widely advertised. As denture brushes and dentifrices are not common in Brazil, it is frequent the use of products originally designed for natural teeth. In addition, these products are not regularly available for purchasing and, when they are, this occurs for short periods of time.

Natural tooth brushes should preferably not be used because they do not have an appropriate shape ${ }^{1}$. There is also indication for using two brushes (a hand brush and a dental brush); brushes with uniform length of bristles, and flexible and rounded tips ${ }^{13}$; specific brushes ${ }^{7}$; custom-made toothbrushes to facilitate cleansing; and soft-bristles denture brushes as a way of limitation to the applied force ${ }^{5,9}$.
Brushing is a simple, low-cost method that is efficient for removal of stains and organic deposits. It has the disadvantages of being not much easy for uncoordinated patients, causing abrasion of the acrylic resin and damage to the reliners. It is essential the use of adequate brushes and auxiliary agents ${ }^{4}$. Chemical agents can be used separately or in association with brushing, the latter being usually recommended ${ }^{2,6,10}$. However, comparative clinical experiments have shown contradictory results regarding the efficacy of these products, attesting the superiority of either the chemical method, the brushing technique or the association of both ${ }^{15}$.

The adoption of adequate hygiene measures is important because it well demonstrated that successfully improving oral conditions of denture wearers depends on establishing a good planning and execution of a denture care protocol ${ }^{11}$. In the present study, denture care improved after the patients began using the cleansing products, which is in

TABLE 2- Statistical analysis - Friedman's test

\begin{tabular}{|c|c|c|c|c|c|c|c|}
\hline & & & Up & enture & & & \\
\hline Surface & Visit & Bitufo & & Medic Dent & & Colgate & \\
\hline & & Difference & $\mathbf{S}$ & Difference & $\mathbf{S}$ & Difference & $\mathbf{S}$ \\
\hline Internal & $C \times 1^{a}$. & 66.0000 & $1 \%$ & 72.0000 & $1 \%$ & 70.0000 & $1 \%$ \\
\hline & $C \times 2^{a}$ & 71.0000 & $1 \%$ & 65.0000 & $1 \%$ & 68.0000 & $1 \%$ \\
\hline & $\mathrm{C} \times 3^{\mathrm{a}}$ & 61.0000 & $1 \%$ & 61.0000 & $1 \%$ & 60.0000 & $1 \%$ \\
\hline & $1^{\mathrm{a}} \times 2^{\mathrm{a}}$ & 5.0000 & ns & 7.0000 & ns & 2.0000 & ns \\
\hline & $1^{\mathrm{a}} \times 3^{\mathrm{a}}$ & 5.0000 & ns & 11.0000 & ns & 10.0000 & ns \\
\hline & $2^{a} \times 3^{a}$ & 10.0000 & ns & 4.0000 & ns & 8.0000 & ns \\
\hline External & $C \times 1^{a}$ & 71.0000 & $1 \%$ & 60.5000 & $1 \%$ & 69.0000 & $1 \%$ \\
\hline & $\mathrm{C} \times 2^{\mathrm{a}}$ & 73.0000 & $1 \%$ & 70.0000 & $1 \%$ & 66.0000 & $1 \%$ \\
\hline & $C \times 3^{a}$ & 54.0000 & $1 \%$ & 67.5000 & $1 \%$ & 63.0000 & $1 \%$ \\
\hline & $1^{\text {a }} \times 2^{\mathrm{a}}$ & 2.0000 & ns & 9.5000 & ns & 3.0000 & ns \\
\hline & $1^{a} \times 3^{a}$ & 17.0000 & ns & 7.0000 & ns & 6.0000 & ns \\
\hline & $2^{a} \times 3^{a}$ & 19.0000 & ns & 2.5000 & ns & 3.0000 & ns \\
\hline & & & Lov & enture & & & \\
\hline Surface & Visit & Bitufo & & Medic Dent & & Colgate & \\
\hline & & Difference & $\mathbf{s}$ & Difference & $\mathbf{S}$ & Difference & 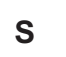 \\
\hline Internal & $\mathrm{C} \times 1^{\mathrm{a}}$ & 66.5000 & $1 \%$ & 74.0000 & $1 \%$ & 73.5000 & $1 \%$ \\
\hline & $\mathrm{C} \times 2^{\mathrm{a}}$ & 66.5000 & $1 \%$ & 63.5000 & $1 \%$ & 60.0000 & $1 \%$ \\
\hline & $C \times 3^{a}$ & 57.0000 & $1 \%$ & 60.5000 & $1 \%$ & 60.5000 & $1 \%$ \\
\hline & $1^{\mathrm{a}} \times 2^{\mathrm{a}}$ & 0.0000 & ns & 10.5000 & $\mathrm{~ns}$ & 13.5000 & ns \\
\hline & $1^{a} \times 3^{a}$ & 9.5000 & ns & 13.5000 & ns & 13.0000 & ns \\
\hline & $2^{a} \times 3^{a}$ & 9.5000 & ns & 3.0000 & ns & 0.5000 & ns \\
\hline External & $\mathrm{C} \times 1^{\mathrm{a}}$ & 70.0000 & $1 \%$ & 69.5000 & $1 \%$ & 68.0000 & $1 \%$ \\
\hline & $\mathrm{C} \times 2^{\mathrm{a}}$ & 68.5000 & $1 \%$ & 62.5000 & $1 \%$ & 64.0000 & $1 \%$ \\
\hline & $C \times 3^{a}$ & 59.5000 & $1 \%$ & 62.0000 & $1 \%$ & 62.0000 & $1 \%$ \\
\hline & $1^{\mathrm{a}} \times 2^{\mathrm{a}}$ & 1.5000 & ns & 7.0000 & ns & 4.0000 & ns \\
\hline & $1^{a} \times 3^{a}$ & 10.5000 & ns & 7.5000 & ns & 6.0000 & ns \\
\hline & $2^{a} \times 3^{a}$ & 9.0000 & ns & 0.5000 & ns & 2.0000 & ns \\
\hline
\end{tabular}

$\mathrm{C}=$ control; Difference = difference between post addition; $\mathrm{S}=$ significance. $\mathrm{ns}=$ non-significance. 
agreement with the findings of previous studies ${ }^{11}$. In fact, this was an expected result because of the institution of a well-defined cleaning regimen and due to the fact that the patients were motivated for being enrolled in a clinical trial. Table 2 (Friedman's test) shows significant differences between the control and the brushing stages. The three brushes showed similar efficacy to each other regarding their ability of biofilm removal. This can be explained by the fact that these brushes were originally designed for denture cleansing and hence have an adequate shape for this role.

The denture surface to be evaluated is an important issue to be considered. The results of the Correlation test (Table 3 ) regarding the comparison of surfaces (internal and external) showed lower correlation coefficients for the upper dentures ( 0.38 to 0.56 ), whereas the lower dentures had more concordant levels of biofilm (correlation coefficients ranging from 0.73 to 0.83 ). These findings can be attributed to the fact that the internal surface of the upper dentures had less biofilm accumulation than the lower dentures. Table 3 also shows the results of the Correlation test between the dentures. When comparing the levels of biofilm between the internal surface of the dentures (upper/lower), the $r$ values were lower (varying from 0.51 to 0.63 ). This fact did not occur when comparing the levels of biofilm on the external surfaces of the dentures (upper/lower), where the levels of biofilm were closer ( $\mathrm{r}$ values varying from 0.78 to

TABLE 3- Results of the Correlation test ( $r$ values)

\section{Correlated Samples \\ Internal x External}

Brushes Upper Denture Lower Denture

\begin{tabular}{lll} 
Bitufo & 0.3846 & 0.7879 \\
Medic Denture & 0.5698 & 0.8341 \\
Colgate & 0.5460 & 0.7362 \\
\hline
\end{tabular}

Upper x Lower

Internal Surface External Surface

\begin{tabular}{lll} 
Bitufo & 0.5129 & 0.8298 \\
Medic Denture & 0.6350 & 0.7869 \\
Colgate & 0.6206 & 0.7955 \\
\hline
\end{tabular}

TABLE 4- Frequency of all kinds of yeasts

\begin{tabular}{|c|c|c|c|c|}
\hline \multirow[t]{2}{*}{ Denture } & \multicolumn{3}{|c|}{ Brushes } & \multirow[b]{2}{*}{ Total } \\
\hline & Bitufo & Medic Denture & Colgate & \\
\hline Upper & 15 & 6 & 10 & 31 \\
\hline Lower & 11 & 6 & 5 & 22 \\
\hline Total & 26 & 12 & 15 & 53 \\
\hline
\end{tabular}

0.82). The comparison between dentures showed low correlation for the internal surface because the upper dentures had less biofilm accumulation than the lower dentures.

Augsburger and Elahi ${ }^{2}$ (1982) showed that convex and smooth surfaces present lower biofilm levels than those artistically sculptured and with sharp finishing. Tarbet, et al. ${ }^{15}$ (1984), in a comparative analysis of denture hygiene products, found significant differences between the internal and external surfaces (right and left buccal flanges) with lower levels of biofilm on the external surface. Similar results have been reported by other authors ${ }^{6,8}$.

The biofilm levels on artificial teeth should also be specifically addressed ${ }^{8}$. In the present study, the area of artificial teeth was included on biofilm assessment and, although a specific analysis of this region has not been made, it clearly had an intense biofilm accumulation, mainly at the site of union of the teeth with the denture base. It is important to remove biofilm from this area to improve esthetics. Pietrokovsky, et al. ${ }^{11}$ (1995) evaluated upper and lower dentures of 249 elders and found that the upper dentures (external and internal surfaces) were cleaner than the lower ones. It was also demonstrated a high correlation between the hygiene levels, when the upper and lower dentures of the same person were compared to each other. Our results are consistent with these findings given that the lower dentures had greater levels of biofilm, mainly in the internal surfaces.

A large number of bacteria is usually found in the microbiota of denture wearers, especially in patients with chronic atrophic candidiasis. Yeasts, however, should not be overlooked as an essential pathogenic microorganism. Firstly, patients with this pathology show a relative or an absolute yeast growth in comparison to those with clinically healthy mucosa. Secondly, there is a significant correlation between the number of yeasts before and after antifungal therapy. In this case, reproduction in agar of the growth sites can be considered on the diagnostic method to identify Candida distribution on denture surfaces, these growth sites correlating with the sites of inflammation on healthy mucosa areas. The technique described by Santarpia, et al. ${ }^{12}$ (1990) is considered an important preventive method in view of the difficulty in eliminating yeasts from infected oral mucosa; on the other hand, a healthy patient may develop the disease.

Table 4 shows a higher frequency of yeasts on upper dentures in comparison to the lower dentures. It may be attributed to the fact that the salivary flow on upper dentures is reduced, which results in low clearance of yeasts. There was no difference among the brushes regarding the frequency of yeasts, although this result may be attributed to the reduced number of patients with microbiological assay.

The three brushes tested in this study were capable of removing biofilm from denture surfaces. Given that there was no statistically significant difference between the brushes, it is assumed that all of them can be routinely used in hygiene programs. Although the consequences of inappropriate denture cleansing are well known the cleaning methods and products are still overlooked or neglected many 
patients and oral health professionals leading to poor denture care, which reduces its clinical longevity.

\section{CONCLUSIONS}

Under the tested conditions, it may be concluded that all denture brushes evaluated in this study were effective in the removal of denture biofilm. There was better correlation of biofilm levels between the surfaces for the lower dentures, and between the dentures for the external surface. There was no difference among the brushes regarding the frequency of yeasts.

\section{ACKNOWLEDGEMENTS}

The authors thank VIPI for supplying the artificial teeth used in the dentures.

\section{REFERENCES}

1- Apfelbaum D. Un nuevo concepto en cepillos para dentaduras artificiales. Trib Odontol. 1970;54:42-5

2- Augsburger RH, Elahi JM. Evaluation of seven proprietary denture cleansers. J Prosthet Dent. 1982;47:356-9.

3- Fernandes RAG, Zaniquelli O, Paranhos HFO. Análise dos métodos de contagem de pontos e planímetro na quantificação do biofilme da dentadura: um estudo de validação metodológica. Pesqui Odontol Bras. 2002;16:63-8.

4-Gornitsky M, Paradis I, Landaverde G, Malo AM, Velly AM. A clinical and microbiological evaluation of denture cleansers for geriatric patients in long-term care institutions. J Can Dent Assoc. 2002;68:3945

5- Keng SB, Lim M. Denture plaque distribution and the effectiveness of a perborate-containing denture cleanser. Quintessence Int. 1996;27:341-5

6- Kulak-Ozkan Y, Kazazoglu E, Arikan A. Oral Hygiene habits, denture cleanliness, presence of yeasts and stomatitis in elderly people. J Oral Rehabil. 2002:29:300-4

7- McCabe JF, Murray ID, Laurie J, Kelly PJ. A method for scoring denture plaque. Eur J Prosthodont Restor Dent. 1996;4:59-64.

8- Murtomaa H, Meurman JH. Mechanical aids in the prevention of dental diseases in the elderly. Int Dent J. 1992;42:365-72.

9- Nikawa H, Hamada T, Yamashiro H, Kumagai H. A review of in vitro and in vivo methods to evaluate the efficacy of denture cleansers. Int J Prosthodont. 1999;12:153-9

10- Paranhos HFO, Silva CHL. Comparative study of methods for the quantification of biofilm on complete dentures. Pesqui Odontol Bras. 2004; 18:215-23.

11- Pietrokovski J, Azuelos J, Tau S, Mostavoy R. Oral findings in elderly nursing home residents in selected countries: oral hygiene conditions and plaque accumulation on denture surfaces. J Prosthet.Dent. 1995;73:136-41.
12- Santarpia RP, Rener RP, Pollock JJ, Gwinnett AJ. Model system for the in vitro testing of a synthetic histidine peptide against Candida species grown directly on the denture surface of patients with denture stomatitis. J Prosthet Dent. 1990;60:62-70.

13- Sheen SR, Harrison A. Assesment of plaque prevention on dentures using an experimental cleanser. J Prosthet Dent. 2000;84:594-601.

14- Silva CHL, Paranhos HFO, Ito IY. Evidenciadores de biofilme em prótese total: avaliação clínica e antimicrobiana. Pesqui Odontol Bras. 2002;16:270-5.

15-Tarbet WJ, Axelrod S, Minkoff S, Fratarcangelo PA. Denture cleansing: a comparison of two methods. J Prosthet Dent. 1984;51:325 